\title{
Library of Congress News Report : Manual for graphic materials
}

The Library of Congress is currently undertaking a project to develop a manual to supplement chapter 8 of the second edition of Anglo-American Cataloguing Rules (AACR 2), which describes procedures for constructing library catalogues for graphics. Chapter 8 draws its examples primarily from commercially produced audio-visual materials, published or documented artists' prints and photographs, portfolios, and reproductions accompanied by printed information. It barely addresses the problems of handling original graphics, collections, and reproductions of previously existing graphic works. The chapter is geared to public and general libraries with integrated book and non-book collections, and the rules provide little or no guidance for institutions with many original, historical, artistic, archival, and manuscript-like graphic materials.

The first draft of the manual to supplement chapter 8 is being written at the Library, with advice and comment from experienced persons and professional organizations co-ordinated through the Joint Committee on Specialized Cataloguing of the Council of National Library and Information Associations. The CNLIA has also obtained a grant from the Research Resources Program of the National Endowment for the Humanities to enable a committee to meet in Washington, D.C., to prepare the final version of the manual. The Library of Congress hopes to have the first draft available for distribution sometime this summer. The revision committee will probably meet in December.

Pictures are catalogued individually because of their aesthetic value or their historical or iconographic importance. Item-by-item cataloguing, however, may become wasteful when in many instances vast numbers of pictures, especially photographs, derive meaning and importance - like manuscripts and archival papers - as part of a collective whole. Although there are often undeniably good reasons for documenting single items, cataloguing by group has become the only archivally sound and practical way to gain physical and intellectual control over large quantities of material.

The supplementary rules in the planned manual will apply to individual original two-dimensional pictorial works such as a print, drawing, painting, poster, photograph, negative, transparency, or slide; groups of such objects issued in sets or portfolios; photographic or photomechanical reproductions of such works, whether single or issued in sets; and collections or reproductions of such works organized around a person, family group, or corporate body, or gathered together because of the creator or a thematic coherence. 
These rules will be appropriate only for materials felt to be of some significance or permanence by the institution. A catalogue record is needed for accurate inventory control and for providing multiple access points to certain individual works and specific collections. These rules are not intended for pictorial works which may be efficiently serviced by physical arrangement in self-indexing files or on shelves by subject or other category without cataloguing.

Anyone wishing to contribute to this project or to receive a draft of the manual for review and comment should write to or telephone Elisabeth W. Betz, Picture Cataloguing Specialist, Prints and Photographs Division, Library of Congress, Washington, D.C. 20540 (tel. 202-287-5836).

\section{BOOKBINDING - THE MONEY SAVER}

In these days of rising book prices and budgetary constraints it makes good economic sense to consider giving your books a new lease of life by having them rebound rather than discarding them for new copies. Not only will you save money - but we venture to suggest that if you let us use the publishers' jackets your readers will be unable to tell the difference.

Please write for a price list or ask for a representative to call. We are sure you will be pleasantly surprised!

For further information please contact:

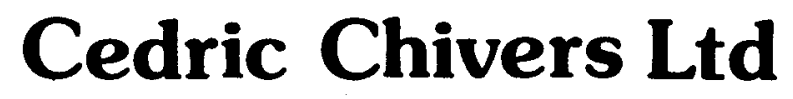

Portway, Combe Park, Bath, BA1 3NF, England.

Telephone: (0225) 23201/2/3 